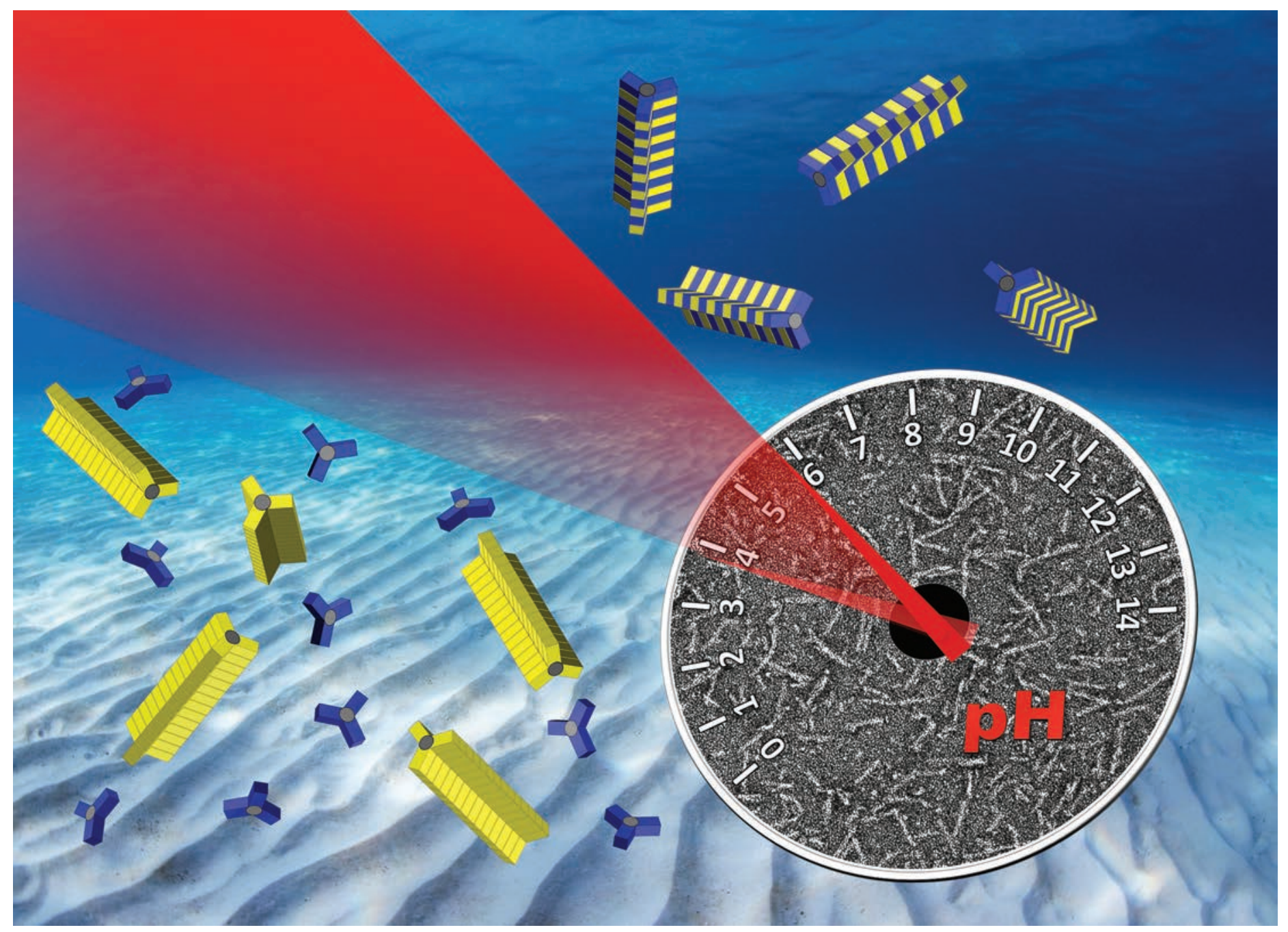

\section{Highlighting research results from the Johannes Gutenberg- Universität in Mainz, Germany.}

Title: Tuneable $\mathrm{pH}$-regulated supramolecular copolymerisation by mixing mismatched dendritic peptide comonomers

Charged phenylalanine-rich dendritic peptides form highly stable and $\mathrm{pH}$-switchable rod-like supramolecular copolymers, when co-assembled with a matching oppositely charged dendritic comonomer. Here, Besenius and coworkers demonstrate that by mismatching a strong with a weak $\beta$-sheet encoded comonomer, both the stability and the $\mathrm{pH}$-triggered disassembly of the copolymers shifts from $\mathrm{pH} 4.2$ to biologically relevant $\mathrm{pH} 5.8$.

\section{As featured in:}

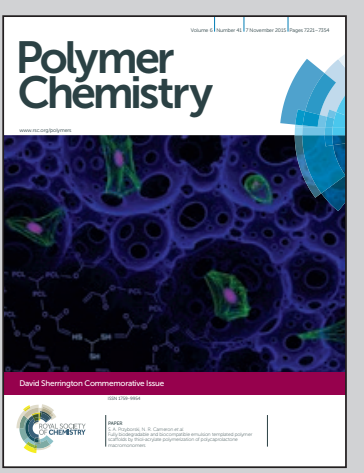

See P. Besenius et al. Polym. Chem., 2015, 6, 7245.

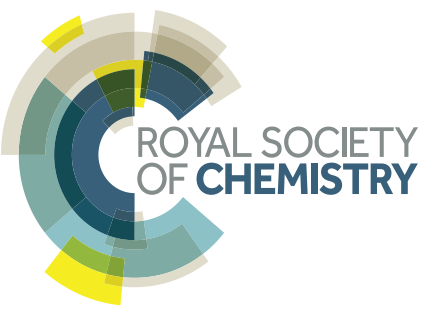




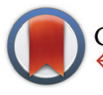

CrossMark \& click for updates

Cite this: Polym. Chem., 2015, 6 , 7245

Received 5th August 2015,

Accepted 17th August 2015

DOI: $10.1039 /$ c5py01241d

www.rsc.org/polymers

\title{
Tuneable pH-regulated supramolecular copolymerisation by mixing mismatched dendritic peptide comonomerst:
}

\author{
P. Ahlers, $\S^{a, b} H$. Frisch $\S^{a, b}$ and P. Besenius ${ }^{* a}$
}

\begin{abstract}
Charged phenylalanine-rich dendritic peptides form highly stable and $\mathrm{pH}$-switchable rod-like supramolecular copolymers, when coassembled with a matching oppositely charged dendritic comonomer. Here, we demonstrate that by mismatching a strong with a weak $\beta$-sheet encoded comonomer, both the stability and the $\mathrm{pH}$-triggered disassembly of the copolymers shifts drastically from $\mathrm{pH} 4.2$ to biologically relevant $\mathrm{pH} 5.8$.
\end{abstract}

Research activities have intensified in using oligopeptide building blocks as supramolecular monomers to form ordered supramolecular polymers and nanostructures in water, demonstrating that rules from the three-dimensional organisation of natural proteins can be translated into the design of peptidebased supramolecular functional materials. ${ }^{1,2}$ A large body of architectures are accessible including cages, spheres, tubes, fibre-like morphologies, tapes and sheet-like arrays. The building blocks are either based on biological derivatives such as collagens, ${ }^{3}$ elastins, ${ }^{4,5} \beta$-sheet systems ${ }^{6-10}$ and $\alpha$-helices/coiledcoils $^{11-16}$ or are based on new design motifs, e.g. cyclic, ${ }^{17,18}$ aliphatic ${ }^{19-21}$ or aromatic amphiphiles, ${ }^{22,23}$ and dendritic oligopeptides. ${ }^{24,25}$ The most exciting features for the development of functional soft matter rely on their robust, yet stimuliresponsive properties, ${ }^{26-29}$ emergence of molecular networks and complex behaviour, ${ }^{30,31}$ and biomedical applications in tissue engineering and regenerative medicine. ${ }^{32,33}$

We have previously reported dendritic anionic and cationic amphiphiles encoded with $\beta$-sheet peptide motifs. ${ }^{25,34}$ These form supramolecular alternating copolymers when mixed in a

\footnotetext{
${ }^{a}$ Institut für Organische Chemie, Johannes Gutenberg-Universität Mainz, Duesbergweg 10-14, 55128 Mainz, Germany. E-mail: besenius@uni-mainz.de; Tel: +4961313922355

${ }^{b}$ Organisch-Chemisches Institut, Westfälische Wilhelms-Universität Münster, Corrensstrasse 40, 48149 Münster, Germany

$\dagger$ We dedicate this paper to Professor David C. Sherrington, an inspiring supervisor and mentor, as well as a true gentleman.

\$Electronic supplementary information (ESI) available: Additional Fig. S1-S14, detailed experimental section: materials, synthesis, characterisation and analysis. See DOI: 10.1039/c5py01241d

$\S$ These authors contributed equally to this work.
}

$1: 1$ feed ratio of the comonomers, and are able to respond to $\mathrm{pH}$ triggers: the self-assembly is only turned on at a neutral $\mathrm{pH}$ when both comonomers are charged. By protonating the anionic glutamic acid (E) comonomer at low pH, or deprotonating the cationic lysine $(\mathrm{K})$ complementary comonomer at high $\mathrm{pH}$, attractive Coulomb interactions are screened. This, in turn, induces the disassembly of the copolymers into the monomers, when using alanine (A) and leucine (L) containing peptides. ${ }^{25}$ The use of aromatic phenylalanine (F) alternated with charged amino acids, does not lead to a simple disassembly of the copolymers, but a pH-triggered copolymer to homopolymer transition, both at low and at high $\mathrm{pH}^{34}{ }^{34}$ Herein we show that long phenylalanine rich dendritic peptides form nanorod-like supramolecular copolymers, that are extremely stable towards changes in $\mathrm{pH}$ and ionic strength. Shortening the peptide sequence via the removal of just one aromatic amino acid reduces the stability, due to reduced hydrophobic shielding of hydrogen bonding and Coulomb attractive interactions. Crucially, we demonstrate that by co-assembling a stronger $\beta$-sheet comonomer, with the second weaker $\beta$-sheet one, the stability of the copolymers is reduced and the $\mathrm{pH}$-triggered disassembly for the copolymers is shifted from $\mathrm{pH} 4.2$ to biologically relevant $\mathrm{pH}$ 5.8. A change in the $\mathrm{pH}$ value as the stimulus for a programmed material respons $\mathrm{e}^{35}$ opens exciting avenues in biomedical applications. ${ }^{36}$ In living cells and tissues, intra- and extracellular $\mathrm{pH}$ values are tightly regulated, but can deviate from $\mathrm{pH}$ neutral and drop to $\mathrm{pH}$ 5.5-6, as observed for example in tumorous, inflammatory sites, in endocytic pathways and specific cellular compartments. ${ }^{37,38}$ We refer to the reported tuneable pH-regulated polymerisation as "comonomer mismatch". We expect it to have an important impact on the design of oligopeptide based delivery vehicles, where the triggered disassembly of surface functionalised polycationic scaffolds into monomeric building blocks is an exciting strategy to release oligonucleotide after the loss of multivalent points of interaction. ${ }^{39-42}$ This phenomenon is somewhat similar to native protein cages, whereby the release of cargo material in intracellular compartments occurs via a delicate balance of decrease in $\mathrm{pH}$ and osmotic swelling. 
A)
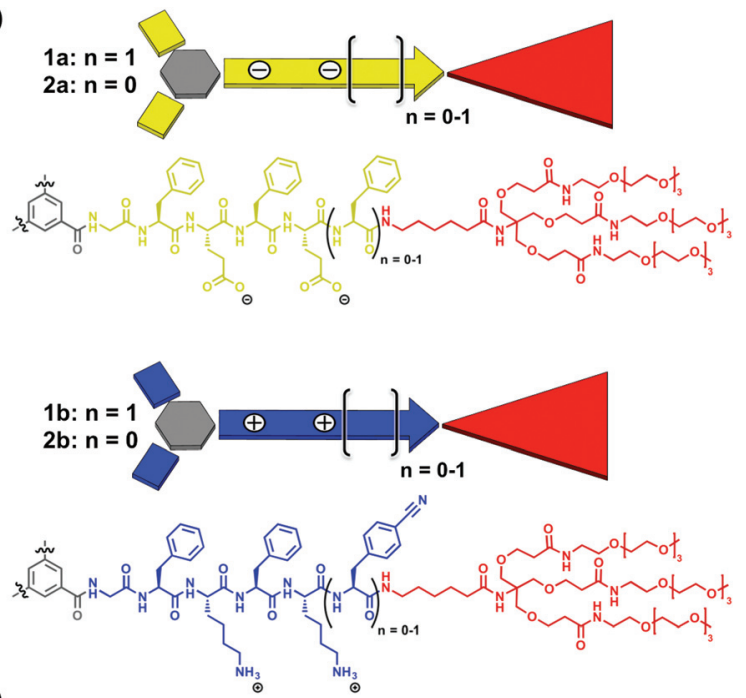

B)

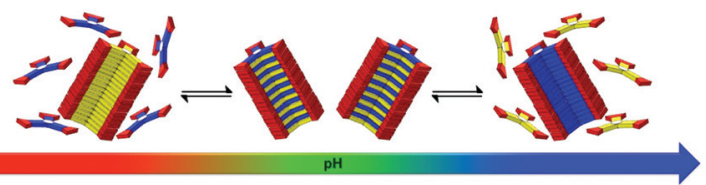

Fig. 1 Chemical structures of the $\mathrm{C}_{3}$-symmetrical dendritic peptide comonomers $1 \mathrm{a}, \mathbf{1 b}$ and $\mathbf{2 a}, \mathbf{2 b}(\mathrm{A})$ and their $\mathrm{pH}$-regulated supramolecular polymerisation into copolymers at neutral $\mathrm{pH}$, and homopolymers at high and low $\mathrm{pH}$ respectively (B).

All four $\mathrm{C}_{3}$-symmetrical dendritic peptide comonomers 1a, $\mathbf{1 b}$ and $2 \mathbf{a}, \mathbf{2 b}$ were synthesised using a convergent synthetic approach. ${ }^{34}$ We have incorporated hydrophobic FE and FK based alternating amino acid sequences in each side arm of the $\mathrm{C}_{3}$-symmetrical comonomers, including an apolar hexylspacer separating the peptide block from a water solubilising tetraethylene glycol peripheral dendron (Fig. 1). The latter were introduced as reported previously in order to increase the solubility of the materials. ${ }^{25,34}$ Note that in the cationic comonomer $\mathbf{1 b}$, we incorporated a C-terminal $p$-cyanophenylalanine (Cnf), instead of phenylalanine on the complementary anionic comonomer 1a, as an optical probe. This leads to an unambiguous differentiation of homo- and copolymers via circular dichroism (CD) spectroscopy. The detailed synthesis and characterisation of the amphiphilic anionic and cationic peptide comonomers 1a (using a GFEFEF peptide sequence), 1b (GFKFKCnf), 2a (GFEFE) and 2b (GFKFK) can be found in the ESI.:

CD spectroscopy experiments using the isolated solutions of comonomers at neutral $\mathrm{pH}$ show weak positive $\mathrm{CD}$ bands at $\lambda=220 \mathrm{~nm}$ for $1 \mathbf{a}$ and $\mathbf{1 b}$ (Fig. $2 \mathrm{~A}$ and B). There is no indication of self-assembly into homopolymers, as expected due to Coulomb repulsion between monomers of the same charge. However by changing the $\mathrm{pH}$, we observe the triggered selfassembly into homopolymers for $\mathbf{1 a}$ at $\mathrm{pH} 5.2$ and $\mathbf{1 b}$ at $\mathrm{pH}$ 10.3. The changes in CD bands are significant with the appearance of a strong negative band at $\lambda=212 \mathrm{~nm}$ (Fig. 2A and B). We observe a shift in the apparent $\mathrm{p} K_{\mathrm{a}}$ values for the dendritic
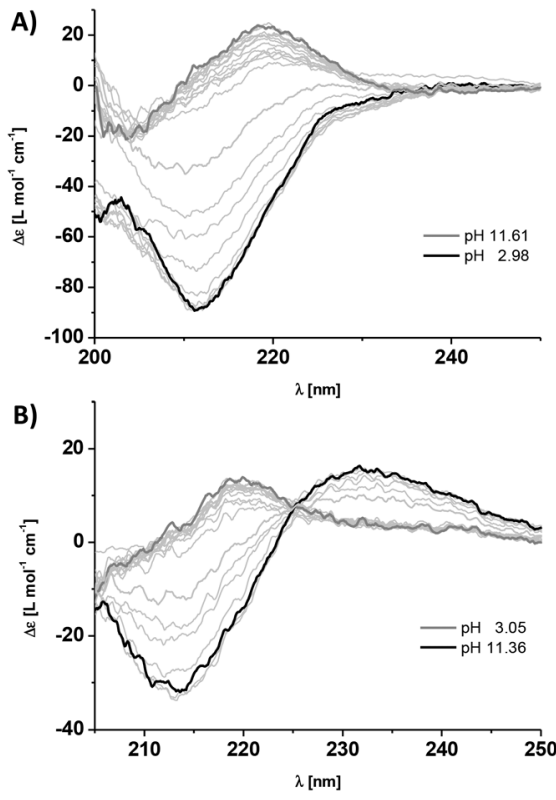

Fig. 2 Titration experiments and $C D$ spectra of a $60 \mu \mathrm{M}$ aqueous solution of monomer $1 \mathrm{a}(\mathrm{A})$ and monomer $1 \mathrm{~b}(\mathrm{~B})$ at different $\mathrm{pH}$ values in $10 \mathrm{mM}$ phosphate buffer at $293 \mathrm{~K}$. The black spectra represent the selfassembled state into homopolymers $(\mathrm{pH} 2.98$ for $1 \mathrm{a}$ and $\mathrm{pH} 11.61$ for $1 b)$, and the dark grey spectra (thick lines) the monomeric state $(\mathrm{pH}$ 11.36 for $1 \mathrm{a}$ and $\mathrm{pH} 3.05$ for $1 \mathrm{~b})$.

peptides compared to the isolated amino acids of 4.3 for glutamic acid and 10.5 for lysine, most likely driven by the aggregation process. We were furthermore able to perform ionic strength dependent experiments for monomer 1a. Increasing the concentration of $\mathrm{NaCl}$ to $>500 \mathrm{mM}$ shifts the monomer to homopolymer transition to slightly higher $\mathrm{pH}$ values, due to the increased thermodynamic driving force for supramolecular polymerisation of the very hydrophobic phenylalanine containing building blocks (Fig. S1 ). This finding is in agreement with our previous investigations on frustrated self-assemblies, whereby due to the electrostatic screening of the negative charges of carboxylate side-chains, the supramolecular polymerisation becomes more favourable at higher ionic strength and neutral $\mathrm{pH}^{43-45}$ Mixing both monomeric building blocks in a $1: 1$ ratio at $\mathrm{pH}=7.4$ instantly leads to a strong negative $\mathrm{CD}$ band at $\lambda=212 \mathrm{~nm}$ characteristic for $\beta$-sheet formation, which is a strong indication for self-assembly into supramolecular alternating copolymers (Fig. 3A). In the past we have successfully correlated $\mathrm{CD}$ spectral bands with photoluminescence experiments using minimalistic FRET pairs, as well as detailed transmission electron microscopy (TEM) characterisation of the monomers, their homopolymers and hetero-copolymers. ${ }^{34}$

To further elucidate the stability of the $\mathbf{1 a} \mathbf{- 1} \mathbf{b}$ copolymers towards changes in the $\mathrm{pH}$ and ionic strength, we performed titration experiments using CD spectroscopy. To our surprise the copolymers were extremely stable. Upon acidifying the phosphate buffer, the intensity of the CD band at $\lambda=212 \mathrm{~nm}$ only changed at pH 4.2, and by adding base at pH 11.5 (Fig. 3). 

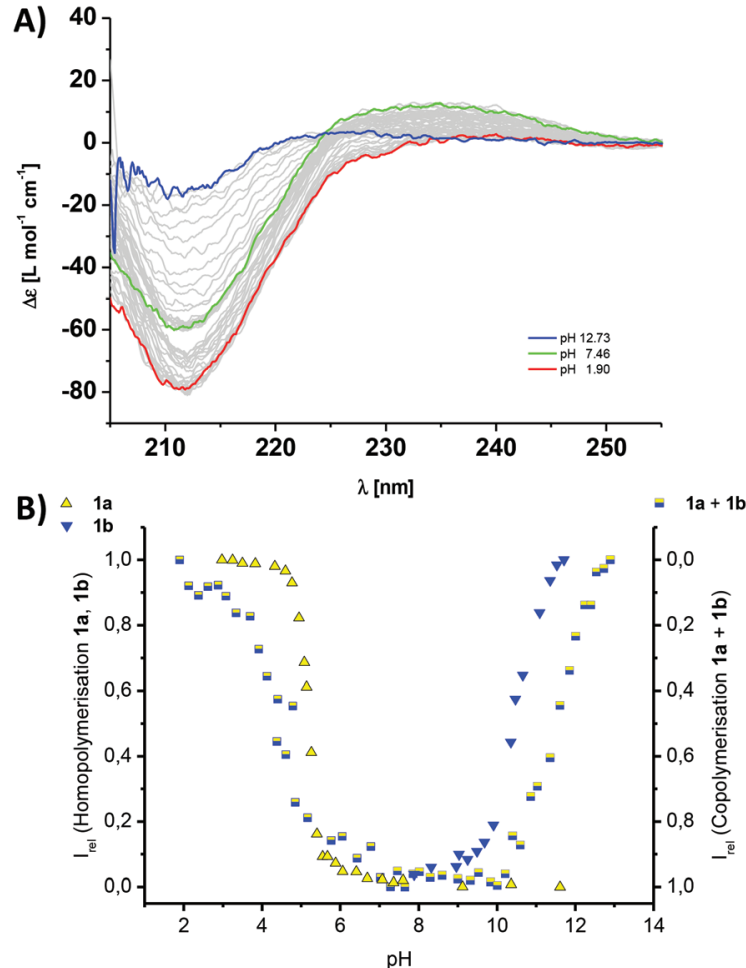

Fig. 3 (A) Titration experiments and CD spectra of a $60 \mu \mathrm{M}$ aqueous solution containing a $1: 1$ mixture of comonomers $1 \mathrm{a}$ and $1 \mathrm{~b}$ at different $\mathrm{pH}$ values in $10 \mathrm{mM}$ phosphate buffer; the black spectrum represents the co-assembled state into copolymers ( $\mathrm{pH} 7.46)$, the yellow spectrum the mixture of homopolymers of $1 \mathrm{a}$ and monomeric $1 \mathrm{~b}(\mathrm{pH} \mathrm{1.9)}$ and the blue spectrum for monomeric $1 \mathrm{a}$ and homopolymers of $1 \mathrm{~b}$ (12.73). (B) The titration curves and normalised CD data for the isolated homopolymerisations (left $y$-axis) of 1a (yellow triangles, Fig. 2A) or 1b (blue triangles, Fig. 2B) and the 1a-1b copolymers (mixed yellow-blue squares, right $y$-axis) following the intensity of the $C D$ band at $\lambda=216 \mathrm{~nm}(\mathrm{~A})$; $I_{\text {rel }}=1$ is set for the polymerised state as 'on' and $I_{\text {rel }}=0$ is set for the polymerised state as switched 'off'.
This is a strong indication that the pH-triggered transition from co- to homopolymers and simultaneous release of the complementary comonomer is shifted by one $\mathrm{pH}$ unit compared to the values expected from the homopolymerisation of the isolated monomer solutions of $1 \mathbf{a}$ and $\mathbf{1 b}$ (Fig. 3B). To confirm that the pH-stability window of the copolymers is increased, we performed $\mathrm{NaCl}$ titrations in neutral phosphate buffer. Remarkably no changes in the characteristic $\beta$-sheet band was observed up to $>1 \mathrm{M} \mathrm{NaCl}$ (Fig. S2 $\$$ ). Phenylalanine rich peptide sequences are the main source of stabilisation for the hydrogen bonded and electrostatics driven $\beta$-sheet formation. In contrast, the previously reported alanine derivates using GAEAE and GAKAK encoded building blocks, disassemble already at $<50 \mathrm{mM} \mathrm{NaCl}$ in phosphate buffer. ${ }^{25}$ We point out that Matile and coworkers have exploited a similar strategy in the $\beta$-sheet directed self-assembly of $p$-octaphenyl $\beta$-barrel pores embedded in lipid bilayers. ${ }^{4-48}$ Due to the spacial proximity and electrostatic repulsion of the charged basic or acidic peptide side chains in these synthetic pores, the intrinsic $\mathrm{p} K_{\mathrm{a}}$ of the base/acid is shifted, an observation which was summarized in an 'intermediate internal charge repulsion' (ICR) model. ${ }^{47,49}$ Here, the balance of attractive and repulsive contributions in the barrel-stave supramolecules is not too dissimlar to our pH-regulated supramolecular co- and homopolymerisation of oppositely charged comonomers: lack of ICR has been suggested to account for 'implosion', low ICR for contraction, high ICR for expansion, and excess ICR for 'explosion' of the $\beta$-barrels.

To correlate the spectroscopic findings with morphological investigations we performed negative stain TEM experiments (Fig. 4 and S5-S14\$). By depositing a solution of either building block 1a at pH 2.0, or $\mathbf{1 b}$ at $\mathrm{pH}$ 12.0, anisotropic nanorodlike structures are obtained (Fig. 4A and B and S5-S8 thickness of the rods $9 \mathrm{~nm}$ is in good agreement with the diameter of the molecular building blocks, which corresponds to an estimated $7.2 \mathrm{~nm}$ for the extended hydrophobic core and

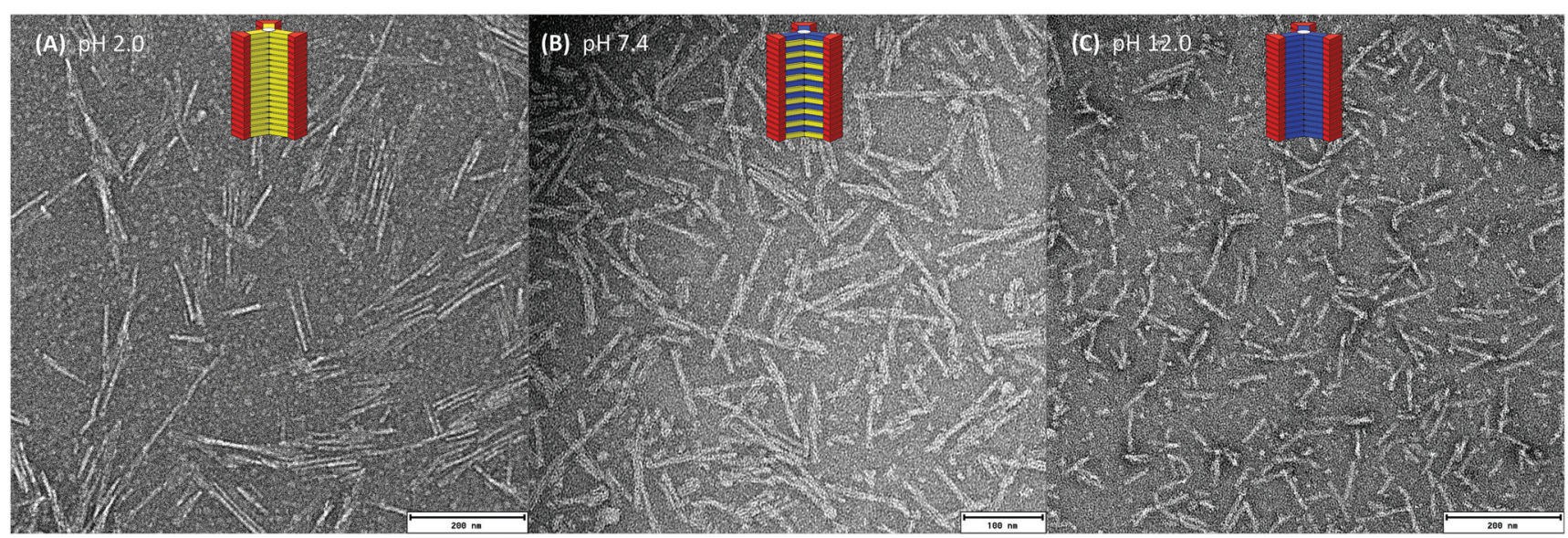

Fig. 4 (A) TEM images of the homopolymer of $1 \mathrm{a}$ at $\mathrm{pH} 2.0$, (B) the 1a-1b copolymer at $\mathrm{pH} 7.4$ and (C) the homopolymer of $1 \mathrm{~b}$ at $\mathrm{pH} 12.0$, in Tris buffer (10 mM); scale bars are $200 \mathrm{~nm}$ (A), (C) and $100 \mathrm{~nm}$ (B). 
$12.5 \mathrm{~nm}$ including the stretched out hydrophilic dendron. If both comonomers are pre-mixed in a $1: 1$ ratio at $\mathrm{pH} 7.4$, welldefined anisotropic structures are observed (Fig. 4C and S9-S10 ). Their thickness of $8 \mathrm{~nm}$ is again in good agreement with the diameter of the molecular buildings blocks.

Due to our interest in using ampholytic supramolecular copolymers as $\mathrm{pH}$-switchable delivery vectors for biomedical applications, we decided to utilise a further pair of the comonomer building blocks 2a (GFEFE) and 2b (GFKFK). These lack the final C-terminal aromatic phenylalanine and $p$-cyanophenylalanine compared to $\mathbf{1 a}$ and $\mathbf{1} \mathbf{b}$. The $\mathrm{pH}$-induced monomer to homopolymer transitions for $\mathbf{2 a}$ at $\mathrm{pH} 5.8$ and $\mathbf{2 b}$ at $\mathrm{pH} 9.2$ were only marginally influenced by the decreased hydrophobicity of the peptide side arms (Fig. 4). $\uparrow$ However the pH titration curves clearly show that the transitions are less sharp. Note that in temperature or concentration dependent supramolecular polymerisations, a more shallow transition would suggest a less cooperative growth mechanism. ${ }^{50-54}$

Our main goal herein was to co-assemble the mismatched comonomer pairs, between a longer and a shorter $\beta$-sheet

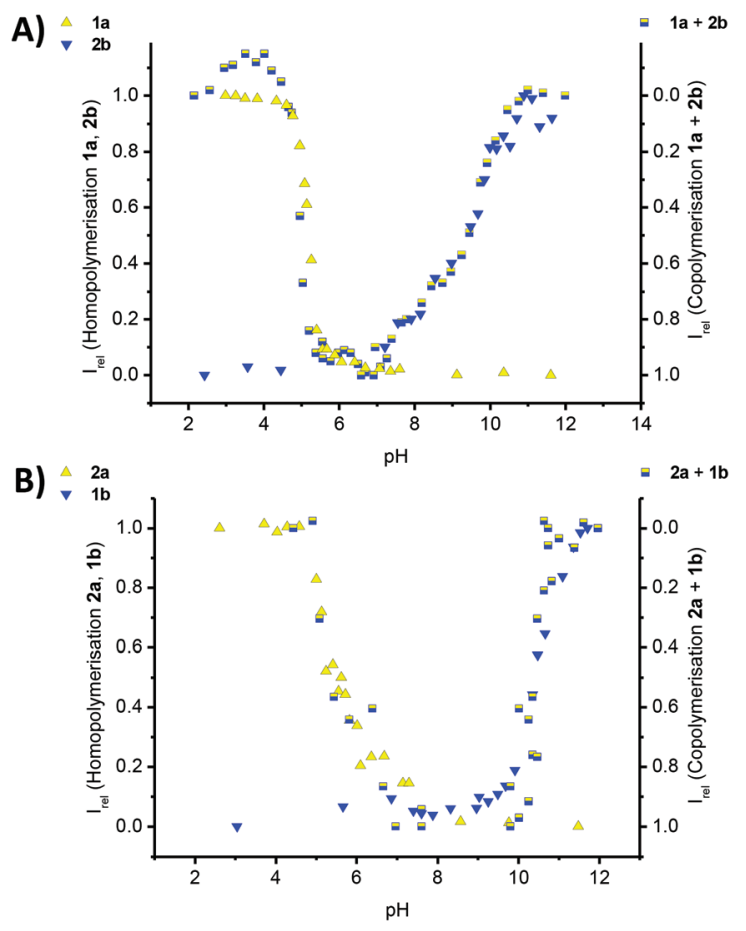

Fig. 5 Titration experiments of $60 \mu \mathrm{M}$ aqueous solutions of monomers in $10 \mathrm{mM}$ phosphate buffer at $293 \mathrm{~K}$; (A) the titration curves for the homopolymerisation of an isolated solution of 1a (yellow triangles, Fig. $2 \mathrm{~A}$ ) and $2 \mathrm{~b}$ (blue triangles, Fig. $\mathrm{S} 4 \mathrm{~B} \ddagger$ ) and the $1 \mathrm{a}-2 \mathrm{~b}$ copolymers (mixed yellow-blue squares, Fig. S3A⿱亠) ); (B) the titration curves and normalised $C D$ data for the homopolymerisation (left $y$-axis) of an isolated solution of $2 \mathrm{a}$ (yellow triangles, Fig. S4A $\ddagger$ ) and $1 \mathrm{~b}$ (blue triangles, Fig. $2 \mathrm{~A}$ ) and the $1 b-2 a$ copolymers (mixed yellow-blue squares, right $y$-axis, Fig. S3B cases, except for the $1 \mathrm{~b}-2 \mathrm{a}$ copolymer $(\lambda=237 \mathrm{~nm}) ; I_{\text {rel }}=1$ is set for the polymerized state as 'on' and $I_{\text {rel }}=0$ is set for the polymerized state as switched 'off'. comonomer and mix $\mathbf{1 a}$ with $\mathbf{2 b}$, or $\mathbf{1 b}$ with $\mathbf{2 a}$. Intriguingly the CD spectroscopic investigations show that both mismatched pairs co-assemble into supramolecular copolymers (Fig. S3 ) (Fig. 5).

The $\mathrm{pH}$ titrations for both $\mathbf{1 a}-\mathbf{2} \mathbf{b}$ and $\mathbf{1} \mathbf{b}-\mathbf{2 a}$ copolymers, lead to $\mathrm{pH}$ curves that reflect our predicted trend. Due to the omission of one hydrophobic amino acid, the thermodynamic stability of the copolymer formation is reduced, the copolymerisation thereby weakened and the $\mathrm{pH}$-stability window of the copolymers narrowed. The copolymer to homopolymer transitions and release of complementary comonomer overlap with the $\mathrm{pH}$ value expected for the homopolymer formation in a solution of the isolated monomer. Furthermore the disassembly of the copolymer is very sharp at low $\mathrm{pH}$ for $\mathbf{1 a}-\mathbf{2} \mathbf{b}$, and at high $\mathrm{pH}$ for $\mathbf{1 b} \mathbf{b} \mathbf{2}$. In the contrary, the transition is shallow at high $\mathrm{pH}$ for $\mathbf{1} \mathbf{a}-\mathbf{2} \mathbf{b}$, and at low $\mathrm{pH}$ for $\mathbf{1} \mathbf{b}-\mathbf{2} \mathbf{a}$. This result is significant for two reasons: first we were able to shift the triggered disassembly from $\mathrm{pH} 4.2$ for $\mathbf{1 a}-\mathbf{1} \mathbf{b}$, to $\mathrm{pH} 5.2$ for $\mathbf{1 a}-\mathbf{2} \mathbf{b}$ and to pH 5.8 for $\mathbf{2 a - 1 b}$. Secondly, the transitions at $\mathrm{pH} 4.2$ and at $\mathrm{pH} 5.2$ are sharp when using the strongly aggregating co-monomer 1a, but more shallow for the transition at $\mathrm{pH} 5.8$ in the case of the weakly aggregating comonomer $2 \mathrm{a}$. Clearly, the choice and design of comonomers dictates the exact $\mathrm{pH}$ at which the disassembly occurs, but also the cooperative response to the external trigger. In case a controlled release of cargo is preferred over burst-type release often observed for conventional micellar assemblies, our design features will have important implications for the structural design parameters of biomedical delivery vehicles.

\section{Conclusions}

In summary, we have synthesised two different pairs of oppositely charged amphiphilic dendritic peptides. These coassemble into $\mathrm{pH}$-switchable nanorod-like supramolecular copolymers in neutral buffer. In the first set of pairs we have used long phenylalanine rich dendritic peptides that are extremely stable towards changes in $\mathrm{pH}$ and ionic strength. By shortening the peptide sequence in the second comonomer pair the removal of a single aromatic amino acid reduces the stability significantly, due to reduced hydrophobic shielding. Crucially we demonstrate that by co-assembling a longer and stronger $\beta$-sheet comonomer, with a second weaker $\beta$-sheet design, the stability of the copolymers is tuneable. The $\mathrm{pH}$-triggered disassembly for the copolymers is shifted from $\mathrm{pH} 4.2$ for the two stronger $\beta$-sheet monomers to biologically relevant pH 5.8 for the mismatched pair between a strong cationic and a weak anionic $\beta$-sheet synthon. We refer to this tuneable $\mathrm{pH}$ regulated polymerisation as comonomer mismatch strategy, and expect it to have an impact on the design of peptidic delivery vehicles for biomedical applications, since the release of cargo material in intracellular compartments is a balance between decrease of the $\mathrm{pH}$ and osmotic swelling. 


\section{Acknowledgements}

We thank Daniel Spitzer (Institut für Organische Chemie, JGU Mainz) Frank Depoix (Institut für Zoologie, JGU Mainz) for help with the TEM experiments, the 'Fonds der Chemischen Industrie' (FCI) for financial support and COST Action CM1005 (Supramolecular Chemistry in Water).

\section{Notes and references}

ๆ For TEM experiments of the self-assembled $\mathbf{2 a}$ and $\mathbf{2 b}$, see Fig. S11-S14

1 T. O. Yeates and J. E. Padilla, Curr. Opin. Struct. Biol., 2002, 12, 464-470.

2 T. Aida, E. W. Meijer and S. I. Stupp, Science, 2012, 335, 813-817.

3 J. A. Fallas, L. E. R. O'Leary and J. D. Hartgerink, Chem. Soc. Rev., 2010, 39, 3510-3527.

4 J. F. Almine, D. V. Bax, S. M. Mithieux, L. Nivison-Smith, J. Rnjak, A. Waterhouse, S. G. Wise and A. S. Weiss, Chem. Soc. Rev., 2010, 39, 3371-3379.

5 S. R. MacEwan and A. Chilkoti, Biopolymers, 2010, 94, 60-77.

6 M. Krejchi, E. Atkins, A. Waddon, M. Fournier, T. Mason and D. Tirrell, Science, 1994, 265, 1427-1432.

7 M. W. West, W. Wang, J. Patterson, J. D. Mancias, J. R. Beasley and M. H. Hecht, Proc. Natl. Acad. Sci. U. S. A., 1999, 96, 11211-11216.

8 S. Zhang, Nat. Biotechnol., 2003, 21, 1171-1178.

9 I. W. Hamley, Angew. Chem., Int. Ed., 2007, 46, 8128-8147.

10 A. Saiani, A. Mohammed, H. Frielinghaus, R. Collins, N. Hodson, C. M. Kielty, M. J. Sherratt and A. F. Miller, Soft Matter, 2009, 5, 193-202.

11 C. Cohen and D. A. D. Parry, Proteins: Struct., Funct., Genet., 1990, 7, 1-15.

12 T. Alber, Curr. Opin. Genet. Dev., 1992, 2, 205-210.

13 R. B. Hill, D. P. Raleigh, A. Lombardi and W. F. DeGrado, Acc. Chem. Res., 2000, 33, 745-754.

14 B. Apostolovic, M. Danial and H.-A. Klok, Chem. Soc. Rev., 2010, 39, 3541-3575.

15 D. N. Woolfson and Z. N. Mahmoud, Chem. Soc. Rev., 2010, 39, 3464-3479.

16 N. R. Zaccai, B. Chi, A. R. Thomson, A. L. Boyle, G. J. Bartlett, M. Bruning, N. Linden, R. B. Sessions, P. J. Booth, R. L. Brady and D. N. Woolfson, Nat. Chem. Biol., 2011, 7, 935-941.

17 R. Chapman, M. Danial, M. L. Koh, K. A. Jolliffe and S. Perrier, Chem. Soc. Rev., 2012, 41, 6023-6041.

18 J. Montenegro, M. R. Ghadiri and J. R. Granja, Acc. Chem. Res., 2013, 46, 2955-2965.

19 J. D. Hartgerink, E. Beniash and S. I. Stupp, Science, 2001, 294, 1684-1688.

20 J. D. Hartgerink, Proc. Natl. Acad. Sci. U. S. A., 2002, 99, 5133-5138.
21 G. A. Silva, C. Czeisler, K. L. Niece, E. Beniash, D. A. Harrington, J. A. Kessler and S. I. Stupp, Science, 2004, 303, 1352-1355.

22 A. M. Smith, R. J. Williams, C. Tang, P. Coppo, R. F. Collins, M. L. Turner, A. Saiani and R. V. Ulijn, Adv. Mater., 2008, 20, 37-41.

23 S. Fleming and R. V. Ulijn, Chem. Soc. Rev., 2014, 43, 81508177.

24 V. Percec, A. E. Dulcey, M. Peterca, M. Ilies, M. J. Sienkowska and P. A. Heiney, J. Am. Chem. Soc., 2005, 127, 17902-17909.

25 H. Frisch, J. P. Unsleber, D. Lüdeker, M. Peterlechner, G. Brunklaus, M. Waller and P. Besenius, Angew. Chem., Int. Ed., 2013, 52, 10097-10101.

26 D. W. P. M. Löwik, E. H. P. Leunissen, M. van den Heuvel, M. B. Hansen and J. C. M. van Hest, Chem. Soc. Rev., 2010, 39, 3394-3412.

27 J. M. Zayed, N. Nouvel, U. Rauwald and O. A. Scherman, Chem. Soc. Rev., 2010, 39, 2806-2816.

28 E. Krieg and B. Rybtchinski, Chem. - Eur. J., 2011, 17, 9016-9026.

29 X. J. Loh, J. del Barrio, T.-C. Lee and O. A. Scherman, Chem. Commun., 2014, 50, 3033-3035.

30 R. F. Ludlow and S. Otto, Chem. Soc. Rev., 2008, 37, 101108.

31 E. Mattia and S. Otto, Nat. Nanotechnol., 2015, 10, 111-119.

32 H. Cui, M. J. Webber and S. I. Stupp, Biopolymers, 2010, 94, 1-18.

33 X. Zhao, F. Pan, H. Xu, M. Yaseen, H. Shan, C. A. E. Hauser, S. Zhang and J. R. Lu, Chem. Soc. Rev., 2010, 39, 3480-3498.

34 H. Frisch, Y. Nie, S. Raunser and P. Besenius, Chem. - Eur. J., 2015, 21, 3304-3309.

35 H. Frisch and P. Besenius, Macromol. Rapid Commun., 2015, 36, 346-363.

36 H. Cabral and K. Kataoka, J. Controlled Release, 2014, 190, 465-476.

37 R. Duncan, Nat. Rev. Drug Discovery, 2003, 2, 347-360.

38 J. R. Casey, S. Grinstein and J. Orlowski, Nat. Rev. Mol. Cell Biol., 2010, 11, 50-61.

39 A. Barnard and D. K. Smith, Angew. Chem., Int. Ed., 2012, 51, 6572-6581.

40 S. K. M. Nalluri, J. Voskuhl, J. B. Bultema, E. J. Boekema and B. J. Ravoo, Angew. Chem., Int. Ed., 2011, 50, 97479751.

41 S. P. Jones, N. P. Gabrielson, D. W. Pack and D. K. Smith, Chem. Commun., 2008, 4700-4702.

42 D. Joester, M. Losson, R. Pugin, H. Heinzelmann, E. Walter, H. P. Merkle and F. Diederich, Angew. Chem., Int. Ed., 2003, 42, 1486-1490.

43 M. von Gröning, I. de Feijter, M. C. A. Stuart, I. K. Voets and P. Besenius, J. Mater. Chem. B, 2013, 1, 2008-2012.

44 P. Ahlers, H. Frisch, D. Spitzer, Z. Vobecka, F. Vilela and P. Besenius, Chem. - Asian J., 2014, 9, 2052-2057.

45 R. Appel, S. Tacke, J. Klingauf and P. Besenius, Org. Biomol. Chem., 2015, 13, 1030-1039. 
46 S. Matile, Chem. Soc. Rev., 2001, 30, 158-167.

47 B. Baumeister, A. Som, G. Das, N. Sakai, F. Vilbois, D. Gerard, S. P. Shahi and S. Matile, Helv. Chim. Acta, 2002, 85, 2740-2753.

48 N. Sakai, J. Mareda and S. Matile, Acc. Chem. Res., 2008, 41, 1354-1365.

49 A. Som and S. Matile, Chem. Biodiversity, 2005, 2, 717729.

50 D. Zhao and J. S. Moore, Org. Biomol. Chem., 2003, 1, 34713491.
51 T. F. A. de Greef, M. M. J. Smulders, M. Wolffs, A. P. H. J. Schenning, R. P. Sijbesma and E. W. Meijer, Chem. Rev., 2009, 109, 5687-5754.

52 Z. Chen, A. Lohr, C. R. Saha-Möller and F. Würthner, Chem. Soc. Rev., 2009, 38, 564-584.

53 M. M. J. Smulders, M. M. L. Nieuwenhuizen, T. F. A. d. Greef, P. van der Schoot, A. P. H. J. Schenning and E. W. Meijer, Chem. - Eur. J., 2010, 16, 362-367.

54 C. Rest, R. Kandanelli and G. Fernandez, Chem. Soc. Rev., 2015, 44, 2543-2572. 